\title{
Printed Graphene Electrochemical Biosensors Fabricated by Inkjet Maskless Lithography for Rapid and Sensitive Detection of Organophosphates
}

\author{
John A. Hondred, ${ }^{\dagger}$ Ji Joyce C. Breger, ${ }^{\ddagger}$ Nathan J. Alves, ${ }^{\ddagger}$ Scott A. Trammell, ${ }^{\ddagger}$ Scott A. Walper, ${ }^{\ddagger}$ \\ Igor L. Medintz, ${ }^{\ddagger}$ and Jonathan C. Claussen $*,+, \S^{\circ}$ \\ ${ }^{\dagger}$ Department of Mechanical Engineering, Iowa State University, Ames, Iowa 50011, United States \\ ${ }^{\ddagger}$ Center for Bio/Molecular Science and Engineering, Code 6900, U. S. Naval Research Laboratory, Washington, D.C. 20375, United \\ States \\ ${ }^{\S}$ Division of Materials Science and Engineering, Ames Laboratory, Ames, Iowa 50011, United States
}

\section{Supporting Information}

ABSTRACT: Solution phase printing of graphene-based electrodes has recently become an attractive low-cost, scalable manufacturing technique to create in-field electrochemical biosensors. Here, we report a graphene-based electrode developed via inkjet maskless lithography (IML) for the direct and rapid monitoring of triple-O linked phosphonate organophosphates (OPs); these constitute the active compounds found in chemical warfare agents and pesticides that exhibit acute toxicity as well as long-term pollution to soils and waterways. The IML-printed graphene electrode is nano/
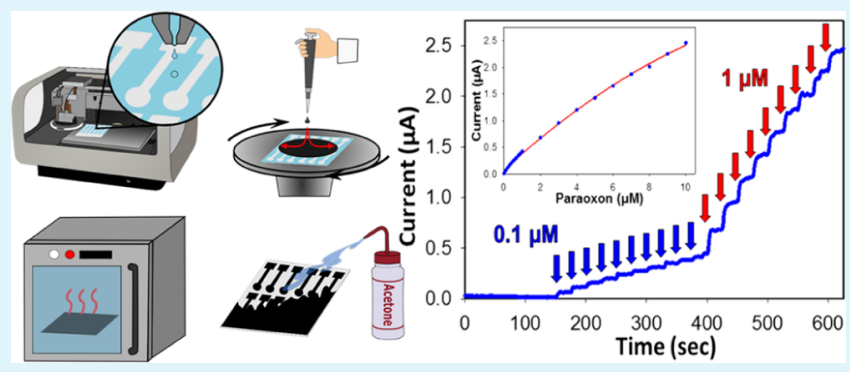
microstructured with a $1000 \mathrm{~mW}$ benchtop laser engraver and electrochemically deposited platinum nanoparticles (dia. $\sim 25 \mathrm{~nm}$ ) to improve its electrical conductivity (sheet resistance decreased from $\sim 10000$ to $100 \Omega / \mathrm{sq}$ ), surface area, and electroactive nature for subsequent enzyme functionalization and biosensing. The enzyme phosphotriesterase (PTE) was conjugated to the electrode surface via glutaraldehyde cross-linking. The resulting biosensor was able to rapidly measure ( $5 \mathrm{~s}$ response time) the insecticide paraoxon (a model OP) with a low detection limit $(3 \mathrm{nM})$, and high sensitivity $(370 \mathrm{nA} / \mu \mathrm{M})$ with negligible interference from similar nerve agents. Moreover, the biosensor exhibited high reusability (average of $0.3 \%$ decrease in sensitivity per sensing event), stability ( $90 \%$ anodic current signal retention over $1000 \mathrm{~s}$ ), longevity (70\% retained sensitivity after 8 weeks), and the ability to selectively sense OP in actual soil and water samples. Hence, this work presents a scalable printed graphene manufacturing technique that can be used to create OP biosensors that are suitable for in-field applications as well as, more generally, for low-cost biosensor test strips that could be incorporated into wearable or disposable sensing paradigms.

KEYWORDS: electrochemical biosensor, graphene, inkjet printing, pesticide, phosphotriesterase, paraoxon

\section{INTRODUCTION}

Organophosphates (OPs) are widely used as insecticides to increase quality and yield of crops. ${ }^{1,2}$ While OPs are effective neurotoxins against several types of pests, they are also toxic to humans and the environment. High-level, acute exposure to OPs can lead to immediate detrimental health effects including miosis, rhinorrhea, apnea, convulsions, and death. ${ }^{3}$ Subsequently, OP neurotoxins have even been weaponized into Gtype chemical warfare agents such as Sarin and Soman, ${ }^{4,5}$ which were used in an 1994 attack in Matsumoto Japan that poisoned 600 residents $^{6}$ and the 1999 Tokyo subway attack injuring 640 victims. ${ }^{7}$ In addition to such high-level acute exposure to OPs, chronic low-level exposure to OP-based pesticides is also a concern especially for farmworkers. ${ }^{8}$ For example, farmworkers in both developed and developing countries who work on fields sprayed with OPs expressed lower neurobehavioral performance than control farmworker groups. ${ }^{9,10}$ Despite their short half-lives (days to months), OP residues have been found in soils, sediments, and watersheds-raising health concerns for chronic and early-life exposure to non-occupational populations especially those living in agricultural communities. ${ }^{11,12}$ Hence, rapid and accurate detection of even low-level concentrations of OPs in the environment is critical for effective remediation measures. ${ }^{13}$ While there are numerous techniques capable of detecting trace levels of OPs (e.g., gas/liquid chromatography, immunoassays, and mass spectroscopy), these tests are timeconsuming and must be performed in a laboratory by trained technicians. $^{14,15}$ Currently, a rapid inexpensive method of monitoring pesticide levels in water or soil slurries in the field does not exist on the market. ${ }^{16}$

Received: December 28, 2017

Accepted: March 5, 2018

Published: March 5, 2018 
Electrochemical, enzymatic biosensors present a promising solution to in-field OP monitoring. ${ }^{17}$ Enzymatic biosensors exhibit favorable characteristics for point-of-service sensing (e.g., high selectivity, sensitivity, and reusability) for a wide variety of applications including medical screening, ${ }^{18}$ defense threat monitoring, ${ }^{19}$ and environmental testing. ${ }^{20}$ OP enzymatic biosensors have primarily focused on using cholinesterase enzymes (i.e., acetylcholinesterase or butyrylcholinesterase) that are inhibited in the presence of OP. ${ }^{21,22}$ While such inhibition-based enzyme biosensors have displayed high sensitivity and ultra-low OP detection limits, they also are prone to false-positive signals as cholinesterase enzymes can be inhibited by heavy metals or detergents that are found in soil and water samples. ${ }^{23}$ Comparatively, the enzyme phosphotriesterase [PTE (EC 3.1.8.1)] selectively binds to OPs via a three O-linked binding pocket that is selective to specific ester bonds found in many OPs such as paraoxon. ${ }^{24}$ PTE catalyzes paraoxon into equimoles of $p$-nitrophenol, an electroactive molecule, which can be readily monitored through direct oxidation at an applied potential of $+0.95 \mathrm{~V}$ versus an $\mathrm{Ag} / \mathrm{AgCl}$ reference electrode. ${ }^{17}$ Electrochemical detection of paraoxon with carbon-based materials (e.g., glassy carbon, graphite, and carbon nanotubes) has been used for the direct amperometric detection of $p$-nitrophenol, due in part to their high biocompatibility with immobilized enzymes and high electrical conductivity. ${ }^{25-30}$ However, because of low sensitivity (limit of detection $\sim 10 \mathrm{nM}$, Table 1 ) and the high cost associated with

Table 1. Performance of Various Direct PTE Amperometric Biosensors $^{a}$

$\begin{array}{lcccc}\text { material/immobilize } & \begin{array}{c}\text { sensitivity } \\ (\mathrm{nA} / \mu \mathrm{M})\end{array} & \begin{array}{c}\text { detection } \\ \text { limit }(\mathrm{nM})\end{array} & \begin{array}{c}\text { linear range } \\ (\mu \mathrm{M})\end{array} & \text { refs } \\ \text { GC-SWNT/EDC-NHS } & 240^{*} & 10 & 0.5-8.5 & 50 \\ \text { GC-CLEC/GA } & 25.95 & 314 & 0.5-2.0 & 34 \\ \text { GC-MWNT/Na-FI } & 25 & 150 & 0.25-4 & 51 \\ \text { FI-Au-Ny/GA } & 2.29 & 100 & 1-10 & 60 \\ \text { MWNT-DNA/PEI } & 74 & 77 & & 61 \\ \text { C-Ny/GA-Si } & 12 & 20 & 0.02-18 & 28 \\ \text { GC-MC-CB/Na } & 198 & 120 & 0.2-8 & 25 \\ \text { C/Na } & 1.45 & 400 & 4.6-46 & 62 \\ \text { GC-MC/Na } & 129 & 9 & 0.5-25 & 52 \\ \text { IML-PGE/GA } & 270 & 12 & 0.1-1 & \text { this } \\ & & & & \text { work } \\ \text { PtNP-IML-PGE/GA } & 370 & 3 & 0.1-1 & \text { this } \\ & & & & \text { work }\end{array}$

${ }^{a} \mathrm{GC}$ - glassy carbon; SWNT-single-walled carbon nanotubes; CLEC-cross-linked enzyme crystals; GA-glutaraldehyde; MWNT-multiwalled carbon nanotubes; Na-Nafion; FI-flow injection; PEI-polyethyleneimine; $\mathrm{C}-$ carbon; $\mathrm{Ny}-\mathrm{Nylon}$; $\mathrm{Si}-$ silicon oil; $\mathrm{MC}-$ mesoporous carbon; $\mathrm{CB}$ - carbon black; PtNPsplatinum nanoparticles; IML-inkjet maskless lithography; PGEpatterned graphene electrodes. *According to interpretation of Figure $5 \mathrm{a}$ in referenced manuscript.

graphene and carbon nanotubes synthesized via chemical vapor deposition, the potential of PTE biosensors for direct, in-field sensing has been limited especially as the maximum allowable OP concentration levels in drinking water begins to approach the sub-nanomolar range (European Union Drinking Water Directive 98/83/EC). ${ }^{31}$

This article addresses three key issues that often hinder enzymatic OP biosensors, i.e., scalable/economical manufacturing processes, surface-fouling, and low sensitivity/high detection limits. Herein, we report the first printed graphene biosensor for amperometric detection of the insecticide paraoxon, a model OP. Graphene electrodes were printed and patterned through a recently developed thin film manufacturing technique called inkjet maskless lithography (IML). ${ }^{32}$ Next, the printed graphene electrodes (PGEs) were laser-annealed and electrochemically deposited with platinum nanoparticles (PtNPs) to create a nano/microstructured surface that is highly conductive/electroactive with a high surface area for increased enzyme loading and heterogeneous charge transport during electrochemical sensing. The graphenebased electrode was consequently biofunctionalized with the enzyme PTE through covalent cross-linking with glutaraldehyde. This biofunctionalized PtNP-IML-PGE demonstrated the lowest recorded detection limit $(3 \mathrm{nM})$ and highest sensitivity $(370 \mathrm{nA} / \mu \mathrm{M})$ for any reported amperometric PTE biosensor to date. Moreover, the biosensor exhibited high reusability (average of $0.3 \%$ decrease in sensitivity per time sensed), stability ( $90 \%$ anodic current over 1000 s), longevity (70\% retained sensitivity after 8 weeks), and selectivity (negligible interference to six similar nerve agents, ability to detect OP in water and soil samples). The performance and potential scalable manufacturing protocols of the PtNP-IML-PGE suggests that they are well-suited for in-field pesticide detection or potential bioterror agent monitoring in actual biological matrices.

\section{METHODS AND MATERIALS}

2.1. Chemicals and Reagents. Completely chemically reduced single layer graphene was purchased from ACS materials (GN1P005). All pesticides (including paraoxon) were obtained from Chem Service $(\mathrm{N}-12816)$. All other chemicals and solvents were purchased from Sigma-Aldrich and were used without any other purification unless otherwise stated. Water was filtered through a B-Pure Water Purification system (resistivity, $18.2 \mathrm{M} \Omega / \mathrm{cm}^{2}$ ). Screen-printed carbon electrodes (SPCE) were purchased from CH Instruments (SE 101). River water was obtained from the Des Moines River in the state of Iowa.

2.2. Preparation and Purification of PTE. The gene encoding PTE (EC 3.1.8.1), also known as OP hydrolase, from Brevundimonas diminuta was synthesized by Genscript with flanking restriction enzyme sites that facilitated transfer to the bacterial expression vector pET28. Protein expression was performed in Escherichia coli strain BL21(DE3) (New England Biolabs, Ipswich, MA) as previously described. $^{33}$ Briefly, cultures were grown in $500 \mathrm{~mL}$ shake flasks containing kanamycin $(25 \mu \mathrm{g} / \mathrm{mL})$ until midlog stage. Expression of recombinant PTE was induced with $1 \mathrm{mM} \beta$-D-isothiogalactopyranoside and continued overnight at $30{ }^{\circ} \mathrm{C}$. Cell pellets were collected by centrifugation and then lysed through a combination of ethylenediaminetetraacetic acid treatment, lysozyme treatment, and sonication. Insoluble material was pelleted via centrifugation and soluble proteins batched to immobilized metal affinity chromatography resin. Following an incubation to allow protein binding and batch washing to remove nonspecifically bound proteins, PTE was eluted with $200 \mathrm{mM}$ imidazole. The recombinant PTE was further purified by fast protein liquid chromatography which also removed the imidazole. The protein concentration was determined using a Nanosight 1000 to measure the absorbance at $280 \mathrm{~nm}$. Calculations were based on the theoretical extinction coefficient and the molecular weight of the protein.

2.3. Biosensor Fabrication. 2.3.1. Printing Graphene via IML. Similar to our work published earlier, graphene electrodes were manufactured through IML. ${ }^{32}$ In summary, $150 \mathrm{mg}$ of ethyl cellulose (viscosity $46 \mathrm{cP}, 5 \%$ in toluene/ethanol 80:20) was completely dissolved in $50 \mathrm{~mL}$ of acetone and $10 \mathrm{~mL}$ of terpineol. Ethyl cellulose was used as a surfactant to increase the surface tension of the ink and subsequently promote graphene flake suspension in the ink and 

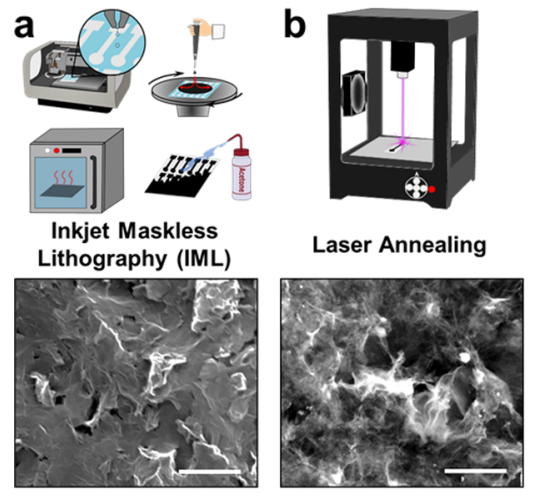

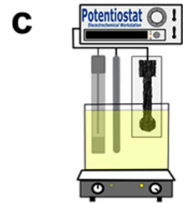

Electrodeposit Platinum NPs

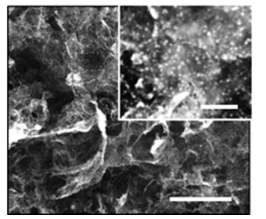

d

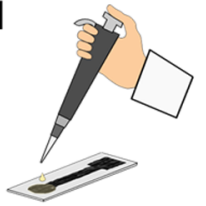

Drop Coat PTE

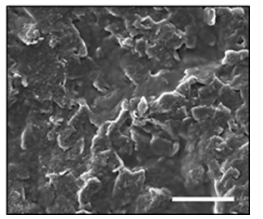

Figure 1. Schematic diagram and corresponding SEM images depicting the fabrication process steps of the PtNP-IML-PGE biosensor. (a) Graphene patterning via the IML technique, (b) laser annealing of IML graphene electrodes, (c) electrodeposition of PtNPs, and (d) drop-coating enzyme (PTE) ink. Bottom: Surface SEM $(15000 \times)$ corresponding to each manufacturing step, scale bar signifies $2 \mu \mathrm{m}$, inset $(250 \mathrm{~nm})$.

improve adhesion of graphene to the substrate upon printing. Pristine graphene flakes $(150 \mathrm{mg})$ were added to the solution and were probesonicated for $4 \mathrm{~h}$. Probe sonication was conducted at $70 \%$ amplitude with a $9 \mathrm{~s}$ pulse and $1 \mathrm{~s}$ rest cycle to reduce graphene size and increase graphene flake exfoliation. The ink was then filtered through a $0.8 \mu \mathrm{m}$ syringe filter. Acetone was evaporated from the solution to yield a concentrated graphene ink $(15 \mathrm{mg} / \mathrm{mL})$ which was spin-coated over an inkjet-printed polymer sacrificial layer ( $10 \%$ formaldehyde resin, $80 \%$ cyclohexanone, $10 \%$ terpineol) on heat-treated polyethylene terephthalate (PET (Kemafoil, Coveme TSL W)). The substrate was then postbaked under a heat gun (Steinel \#HB1750K) for $15 \mathrm{~min}$ at $1200{ }^{\circ} \mathrm{F}$ with a distance of $18 \mathrm{in}$. from the surface. The postbake process significantly improved adhesion of graphene to the substrate without destroying the sacrificial polymer layer. The entire substrate was then impinged with an acetone wash-bottle to remove the sacrificial layer leaving highly defined electrodes (Supporting Information Movie S1).

2.3.2. Laser Annealing. The IML graphene electrodes were laserannealed by a $1000 \mathrm{~mW}$ diode laser engraver (HTPOW). The wavelength of the laser was blue-violet $(405 \mathrm{~nm})$ which did not damage the heat-treated PET substrate. The carving time (i.e., burn time, is the amount of time the laser is positioned at one particular point on the substrate before moving onto a different substrate point) of the engraver was set at $20 \mathrm{~ms}$. This carving time that was found to not degrade/destroy the integrity of the graphene electrode while maximizing its electrical conductivity and electroactive nature (Supporting Information Figures S1 \& S5).

2.3.3. Electrodeposited PtNPs. PtNPs were electrodeposited onto the surface of the electrode using a standard three-electrode setup. A platinum wire $(\mathrm{CH}$ Instruments $\mathrm{CHI115})$ was used as the counter electrode and an $\mathrm{Ag} / \mathrm{AgCl}$ single membrane electrode was used as the reference electrode ( $\mathrm{CH}$ Instruments $\mathrm{CHI11)}$. A platinum electroplating solution of chloroplatinic acid and sodium sulfate was made by mixing $4 \mathrm{mM}$ of $\mathrm{H}_{2} \mathrm{PtCl}_{6}$ and $0.5 \mathrm{M} \mathrm{Na}_{2} \mathrm{SO}_{4}$. The electrode was then placed into the solution, and PtNPs were electrochemically deposited onto the surface by pulsed chronopotentiometry (istep) using pulses or cycles of $0.1 \mathrm{~s}$ steps of $0-250 \mu \mathrm{A}$. This procedure provided high current density across the graphene surface which enhanced the nucleation of PtNPs $(25 \pm 2.5 \mathrm{~nm}, n=25)$ evenly across the graphene surface (Supporting Information Figure S2). The diameter of nanoparticles was determined using scanning electron microscopy (SEM) micrographs (Supporting Information Figure S2) and ImageJ pixel measurement tool with a sample size of $n=25$ PtNPs.

2.3.4. PTE Ink Preparation and Deposition. A PTE ink was developed by mixing $50 \mu \mathrm{L}$ of PTE ( $15 \mu \mathrm{M}$ with a molecular weight of $\sim 35 \mathrm{kDa}), 400 \mu \mathrm{L}$ of deionized water, and $50 \mu \mathrm{L}$ of $50 \mathrm{mg} / \mathrm{mL}$ bovine serum albumin (BSA). The PTE ink was thoroughly mixed using a desktop vortex (Fisher Vortex Mixer \#02215365) on high for $15 \mathrm{~s}$. BSA was added as it has shown to increase the stability of enzymes and to a lesser extent to increase the biosensor sensitivity. ${ }^{34}$ Glutaraldehyde ( $50 \mu \mathrm{L}$ of $0.25 \%$ ) was added to the solution to cross-link the enzyme to the surface of the electrode. The PTE ink was then dropcoated onto the working electrode by hand-pipetting $10 \mu \mathrm{L}$ directly onto the working electrode. The biosensors were then refrigerated $(\sim 4$ ${ }^{\circ} \mathrm{C}$ ) for at least $12 \mathrm{~h}$ during enzyme incubation and were subsequently stored in this environment until biosensor testing.

2.3.5. Electroanalytical Measurements. All electrochemical measurements were conducted using a $\mathrm{CH}$ Instruments potentiostat $(600 \mathrm{E}$ series) with a typical three-electrode setup which included an $\mathrm{Ag} / \mathrm{AgCl}$ reference electrode and a platinum wire counter electrode. All tests were conducted in $15 \mathrm{~mL}$ of phosphate-buffered saline (PBS; 1X, Sigma Aldrich), modified to $\mathrm{pH} 8.0$ with $\mathrm{NaOH}-\mathrm{a}$ pH more favorable to PTE performance (Supporting Information Figure S3). ${ }^{35}$ Cyclic voltammetry $(\mathrm{CV})$ was performed with a $50 \mathrm{mV} / \mathrm{s}$ scan rate; slow scan rates were chosen to minimize surface charging effects because of the double layer capacitance emanating from the high surface area of the laser-annealed graphene. To increase the diffusion of substrate to the enzyme, a magnetic stir bar was added and rotated at $300 \mathrm{rpm}$ for amperometric measurements. Paraoxon stock solution $(1 \mathrm{mM})$ was made daily as it readily photohydrolyzes ${ }^{36}$ and was pipetted at various volumes for desired molarity for all amperometric measurements unless otherwise noted. For selectivity tests, diluted pesticide stock solutions of $0.1 \mathrm{mM}$ were used as many of the tested interference pesticides have low solubility in water. Paraoxon calibration plots for the biofunctionalized PtNP-IML-PGE were conducted with a working potential of $+0.95 \mathrm{~V}(\mathrm{vs} \mathrm{Ag} / \mathrm{AgCl})$ as the biosensor detection limit was minimized at this working potential (Supporting Information Figure S4). To remove the electromagnetic noise that was applied by the magnetic stirrer, data were filtered by taking the running average of 100 points with a scan rate of $0.01 \mathrm{~s}^{-1}$ (running average over $1 \mathrm{~s}$ ). Amperometric biosensor response time was calculated by monitoring the time from the release of target analyte from the pipette tip in the test vial to the time a new steady state current response (90\% max anodic current) was recorded. The biosensor detection limits were calculated using $3 \sigma$ protocols (signal over noise $[\mathrm{S} / \mathrm{N}=3]$, noise estimated from the standard deviation over $25 \mathrm{~s}$ in PBS buffer).

2.3.6. SEM Images. SEM images were acquired using an FEI Quanta 250 FE-SEM. All images were magnified to $15000 \times$ using backscattering electrons, spot size of 4.0 , and with a $10 \mathrm{kV}$ potential. A $2 \mathrm{~nm}$ thick iridium layer was sputter coated onto all imaged samples via a turbo-pump sputter coater to improve imaging by preventing electrons from tunneling through the graphene surface.

\section{RESULTS AND DISCUSSION}

3.1. Overview of the Biosensor Fabrication. Paraoxon biosensors were fabricated by a simple four-step process that utilizes PGEs in lieu of graphene synthesized by chemical vapor deposition-a process requiring a high temperature (up to $1000{ }^{\circ} \mathrm{C}$ ) vacuum synthesis environment that is costly and not well-suited for scalable manufacturing (Figure 1 \& Methods 

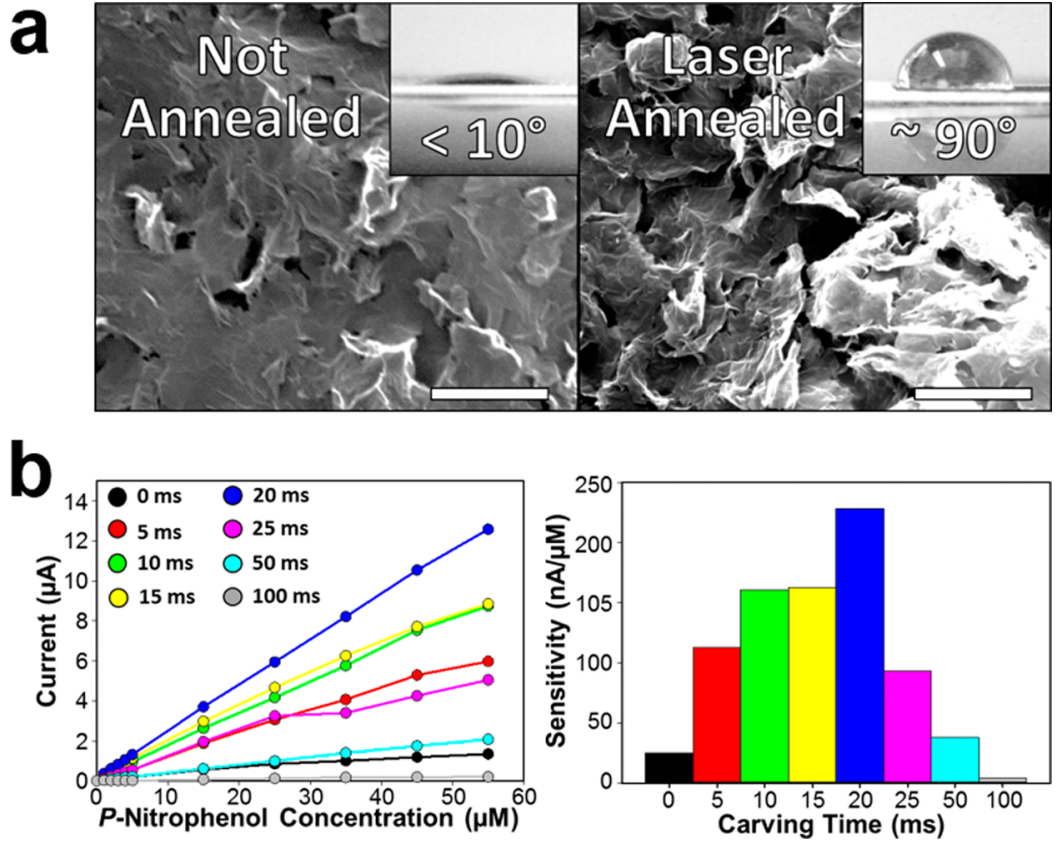

Figure 2. SEM images portraying IML-printed graphene (a) without and with laser annealing (20 ms carving time). Insets display corresponding water contact angle measurements. (b) Amperometric calibration plot of $p$-nitrophenol for the IML-PGE that has been laser-annealed with distinct carving times $(0-100 \mathrm{~ms})$ (left). Histogram of $p$-nitrophenol sensitivity vs laser carving time (right).

and Materials). ${ }^{37}$ The PGEs used herein were first fabricated through our previously reported IML technique ${ }^{32}$ that includes inkjet printing a polymer mask, spin-coating a graphene flake solution, thermal postbaking the printed graphene, and finally performing an acetone rinse lift-off to form well-defined electrode patterns with a $5 \mathrm{~mm}$ diameter disk-shaped working electrode (Figure 1a). After the graphene patterning process, a laser diode engraver was used to anneal the graphene and remove nonconductive ink surfactants (Figure $1 \mathrm{~b}$ ). This laser annealing process significantly improves the electrical conductivity of the PGEs (sheet resistance decreases from $\sim 10000$ to $100 \Omega /$ sq) and adhesion of the graphene to the underlying PET surface while simultaneously nano/microstructuring the graphene surface, which increases the electrode surface area and electroactivity (Figure 1b). Next, PtNPs (diam. $\sim 25 \mathrm{~nm}$ ) were decorated onto the laser-annealed graphene through pulsed electrodeposition to further improve the electroreactivity of the biosensor (Figure 1c). Finally, PTE ink was drop-coated onto the graphene platinum hybrid surface and consequently covalently bound to the surface via glutaraldehyde cross-linking (Figure 1d).

3.1.1. Laser Annealing Process. The electrical conductivity of the IML-PGE was significantly increased by a laser annealing technique (see Methods and Materials). ${ }^{24}$ The laser carving time (inversely proportional to raster rate) was incrementally increased from 5 to $20 \mathrm{~ms}$ which subsequently decreased the graphene sheet resistance 2 orders of magnitude from $\sim 10000$ to $100 \Omega / \mathrm{sq}$ (Supporting Information Figure S5) while increasing the porosity and micro/nanostructuring of the graphene surface (Figure 2a and Supporting Information Figure S1) resulting in a high electroactive surface (from no electroactive surface area to $53 \mathrm{~mm}^{2}$ for non-annealed IMLPGE to $20 \mathrm{~ms}$ laser-annealed IML-PGE, respectively, see Supporting Information Figure S6). The electroactive surface area of the laser-annealed IML-PGE was calculated using the Randles-Sevcik equation (eq 1 ). ${ }^{38,39}$

$$
i_{\mathrm{p}}=2.69 \times 10^{5} A D^{1 / 2} n^{3 / 2} v^{1 / 2} \mathrm{C}
$$

where $n$ is the number of electrons in the faradaic reaction $(n=$ $1), A$ is the effective electroactive surface area $\left(\mathrm{cm}^{2}\right), D$ is the diffusion coefficient $\left(7.6 \times 10^{-6} \mathrm{~cm}^{2} / \mathrm{s}\right), C$ is the concentration of the bulk redox species $(5 \mathrm{mM}), v$ is the scan rate $(\mathrm{V} / \mathrm{s})$, and $i_{\mathrm{p}}$ is the current $(\mathrm{A})$ at the oxidation peak acquired from the cyclic voltammograms in Figure S6. Such increases in electrical conductivity and electroactive surface area significantly improve the oxidation rate of $p$-nitrophenol at the electrode surface as the sensitivity increases from 25 to $230 \mathrm{nA} / \mu \mathrm{M}$ (Figure $2 \mathrm{~b}$ ). However, further increases in the laser carving time (i.e., 50 and $100 \mathrm{~ms}$ ) begins to smooth the IML-PGE surface (electroactive surface area decreases from $53 \mathrm{~mm}^{2}$ at $20 \mathrm{~ms}$ to $10 \mathrm{~mm}^{2}$ at 100 ms, see Supporting Information Figures S1 \& S6) by enhancing interflake bonding via reforming of van der Waals bonds. ${ }^{40,41}$ Subsequently, this graphene smoothing process significantly decreases the sensitivity of the electrode, 3 orders of magnitude from 230 to $3 \mathrm{nA} / \mu \mathrm{M}$, respectively. Hence, the IML-PGEs used for all future experiments in this work are laser-annealed with a carving time of $20 \mathrm{~ms}$.

The laser annealing process most likely increased the electrical conductivity of the IML-printed graphene because of its ability to thermally degrade/destroy nonconductive surfactants and binders still present in the patterned graphene as well as to weld or sinter together individual printed graphene flakes $^{32,40}$ Note that this laser does not degrade the PET underlayer and can be tuned to not harm even paper-based substrates. $^{40}$ Additionally, this laser annealing process, performed in ambient air, increases the number of superficial defects while adding oxygenated species $(\mathrm{COOH},-\mathrm{C}=\mathrm{O}$, and $-\mathrm{OH})$ to the said defects as previously reported. ${ }^{42}$ The increase of graphene superficial defects has been shown to significantly increase the nucleation density of PtNPs during electrodeposition. ${ }^{43}$ Such superficial oxygen species are well-suited for subsequent enzymatic biofunctionalization via glutaraldehyde 

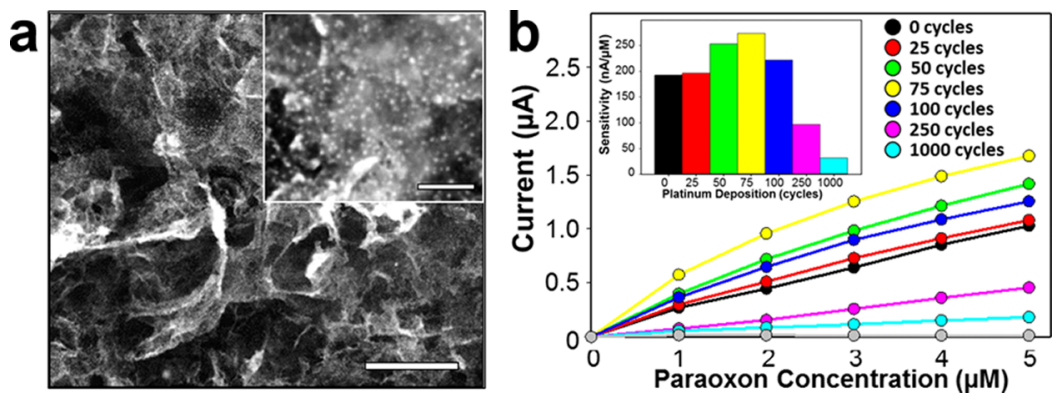

Figure 3. Platinum deposition. (a) SEM micrographs displaying the decorating of PtNPs (diam. $\sim 25 \mathrm{~nm}$ ) on the IML-PGE surface. Scale bar is 5 $\mu \mathrm{m}$ and the inset scale bar is $200 \mathrm{~nm}$. (b) Paraoxon calibration plot for IML-PGEs with increasing electrodeposition cycles. Inset: Histogram depicting the sensitivity of the PtNP-IML-PGE to paraoxon.

cross-linking as hydroxyl groups on the graphene surface bind to the aldehyde groups in glutaraldehyde. ${ }^{44}$ Moreover, this micro/nanostructuring also changed the surface wettability of the graphene from one that is hydrophilic [water contact angle $\left.(\mathrm{CA})<10^{\circ}\right]$ to one that is hydrophobic $\left(\mathrm{CA} \approx 90^{\circ}\right.$ ) (insets of Figure $2 \mathrm{a}) .^{41}$ Such a hydrophobic electrode surface has been shown to repel the electrolyte sensing solution that consequently reduces the double layer capacitance and decreases the sensor background current; hydrophobic electrodes generally increase the signal-to-noise ratio of the output signal. $^{45}$ Moreover, hydrophobic electrodes are generally less susceptible to surface-fouling as they tend to reduce the adsorption of nonspecific species that may be endogenously found in biological matrices. ${ }^{46-48}$

3.1.2. PtNP Decoration. PtNPs ( $25 \mathrm{~nm}$ in diameter) were electrodeposited onto the IML-PGE to further increase their electrocatalytic nature to $p$-nitrophenol oxidation (see Methods and Materials, Figure 3a). ${ }^{49}$ Initially, the incorporation of PtNPs on the surface of the graphene improved the biosensor sensitivity to paraoxon (note the electrode was functionalized with PTE for this experiment, see section 3.1.3) as the number of deposition pulses or cycles increases (0-75 cycles corresponding to 195 and $275 \mathrm{nA} / \mu \mathrm{M}$, respectively, Figure 3b). However, after 75 electrodeposition cycles, larger ridge-like macrostructures were formed (Supporting Information Figure S2), which significantly decreases the sensitivity (1000 cycles corresponding to $32 \mathrm{nA} / \mu \mathrm{M}$, Figure $3 \mathrm{~b}$ ). This decrease in sensitivity is most likely due to the lower surface area and less catalytic capability of larger PtNP macrostructures as opposed to smaller PtNPs as previously illustrated with glucose biosensors fabricated with platinum nano/microparticles electrodeposited on chemical vapor deposition-synthesized multilayer graphene. ${ }^{43}$

$\mathrm{CV}$ was conducted to measure and compare the electrochemical sensitivity to $p$-nitrophenol with a SPCE to that of an IML-PGE that has been laser-annealed as well as decorated with PtNPs (PtNP-IML-PGE) (Figure 4a \& Supporting Information S7). All electrodes displayed distinct anodic peaks at an applied potential of $+0.95 \mathrm{~V}$ versus $\mathrm{Ag} / \mathrm{AgCl}$, which corresponds to the oxidation of $p$-nitrophenol (1 mM). The IML-PGE and PtNP-IML-PGE both display a substantial increase in sensitivity to $p$-nitrophenol over the SPCE as faradaic oxidation peaks (at $+0.95 \mathrm{~V}$ ) were exhibited as follows: $\mathrm{SPCE} \approx 3 \mu \mathrm{A}$, IML-PGE $\approx 10 \mu \mathrm{A}$, and PtNP-IML-PGE $\approx 13$ $\mu \mathrm{A}$ (Figure $4 \mathrm{a})$. After the first scan cycle, the anodic current of the SPCE significantly decreased (>90\%) because of surfacefouling (Figure 4a and Supporting Information Figure S7). As $p$-nitrophenol oxidizes, the phenol-leaving group polymerizes
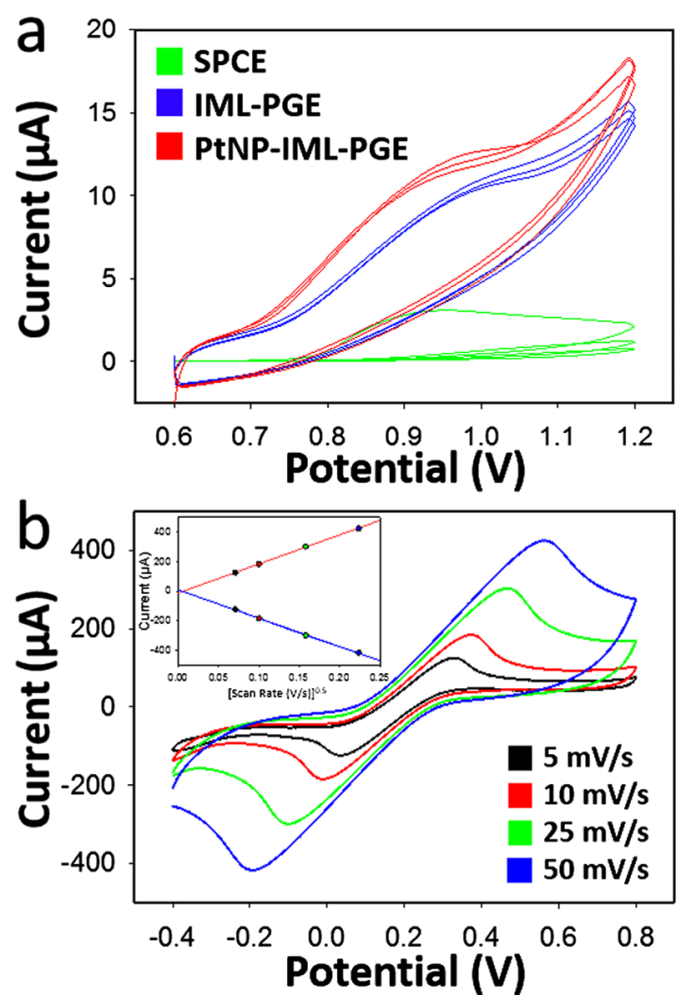

Figure 4. Transduction layer characterization. (a) Cyclic voltammogram showing three repetitive scans in $1 \mathrm{mM} p$-nitrophenol with SPCE (green), laser-annealed IML-PGE (blue), and laser-annealed PtNPIML-PGE (red). (b) Cyclic voltammogram of laser-annealed PtNPIML-PGE in $5 \mathrm{mM}$ ferro/ferricyanide with various scan rates $(5-50$ $\mathrm{mV} / \mathrm{s}$ ). Inset: Randles-Sevcik plot: anodic and cathodic currents vs square root of scan rate.

on the surface of the electrode creating an insulating/diffusion barrier. Comparatively, both the IML-PGE and the PtNP-IMLPGE greatly resisted surface-fouling and decrease faradic current by less than $5 \%$. We speculate that this resistance to surface-fouling is most likely due to the hydrophobic nature of the IML-PGEs as previously mentioned; similarly, other carbon nanomaterials have reported varying degrees of antifouling properties. $^{50-52}$

The surface area of a SPCE and laser-annealed IML-PGE and PtNP-IML-PGE were evaluated by performing CV in ferri/ ferrocyanide (Figure $4 \mathrm{~b}$ and Supporting Information Figure S6). The anodic and cathodic currents both increase in magnitude with faster scan rates and were plotted verses the square root of the scan rate. The linearity demonstrates that the 
process is diffusion-controlled; however, the faradaic peaks shift further apart-a characteristic that is commonly attributed to porous materials that experience slower target analyte diffusion rates. ${ }^{53}$ Using the Randles-Sevcik equation (eq 1 \& Supporting Information Figure S6), the electrochemically active surface area was estimated as 5, 53, and $56 \mathrm{~mm}^{2}$ for SPCE, laserannealed IML-PGE, and laser-annealed PtNP-IML-PGE, respectively.

3.1.3. Enzyme Characterization and Functionalization. The enzyme PTE was converted into an ink with BSA and glutaraldehyde and assayed to monitor and improve its performance (see Methods and Materials). First, it should be noted that as paraoxon diffuses to the electrode surface, PTE catalyzes paraoxon into $p$-nitrophenol which is consequently oxidized at the PtNP-IML-PGE surface during electrochemical biosensing (Figure 5a). However, before electrochemical
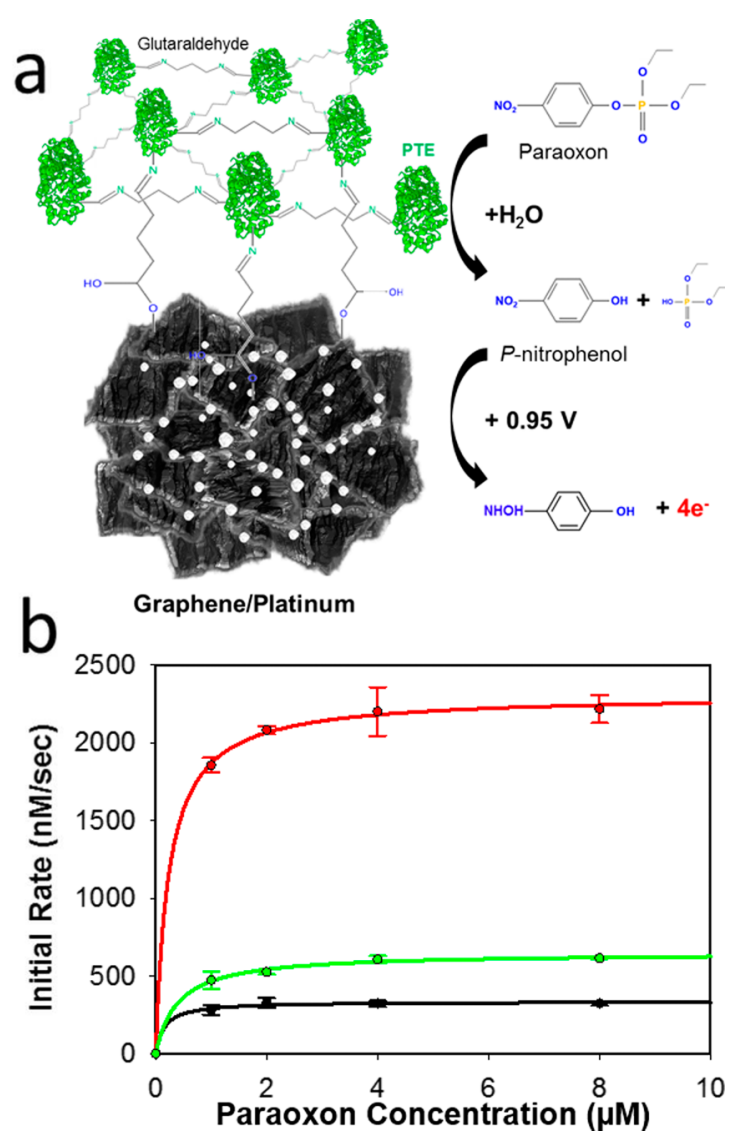

Figure 5. (a) Schematic diagram of PTE functionalized via glutaraldehyde to the PtNP-IML-PGE surface. Hydrolysis of paraoxon into $p$-nitrophenol due to the immobilized PTE enzyme and subsequent oxidation of $p$-nitrophenol at the graphene electrode surface operating with a working potential of $+0.95 \mathrm{~V} \mathrm{vs} \mathrm{Ag} / \mathrm{AgCl}$. (b) Enzyme progress curve displaying the rate of $p$-nitrophenol production for various concentrations of paraoxon with enzyme inks created with distinct concentrations of PTE: $2 \mathrm{nM}$ (black), $4 \mathrm{nM}$ (green), and 20 $\mathrm{nM}$ (red).

biosensing, absorption spectroscopy was used to verify the activity of the PTE that was expressed in E. coli strain BL21(DE3) (see Methods and Materials). The enzymatic activity of the resultant PTE ink was fluorescently monitored in a plate reader assay. PTE degrades paraoxon by hydrolyzing the $\mathrm{P}-\mathrm{O}$ bond yielding diethyl phosphate and $p$-nitrophenol, which has a strong absorption at $405 \mathrm{~nm}$ with an extinction coefficient of $\sim 18000 \mathrm{M}^{-1} \mathrm{~cm}^{-1}$, opposed to paraoxon which has minimal absorption (Figure 5a). ${ }^{54}$ Similar to methods described, ${ }^{55}$ three varying ratios of PTE ink $(0.5,1$, and $5 \%$ which accounts for 2 , 4 , and $20 \mathrm{nM}$ PTE) were assayed versus varying concentrations of paraoxon $(1,2,4$, and $8 \mu \mathrm{M})$. A standard enzymatic rate reaction model was constructed using Sigma plot's enzyme module (Figure $5 \mathrm{~b}$ ). As expected the higher concentration of PTE yielded higher $V_{\max }$ as more substrate can hydrolyze more paraoxon, $\sim 350, \sim 650, \sim 2300 \mathrm{nM} / \mathrm{s} \quad(0.5,1$, and $5 \%$, respectively). All three ink concentrations yielded similar data for $k_{\text {cat }}$ (turnover number), $K_{\mathrm{M}}$ (Michaelis constant), and $k_{\text {cat }} /$ $K_{\mathrm{M}}$ (enzymatic efficiency) of $\sim 160 \mathrm{~s}^{-1}, \sim 0.270 \mu \mathrm{M}$, and $\sim 590$ $\mu \mathrm{M}^{-1} \mathrm{~s}^{-1}$, respectively. These enzyme performance characteristics were a slight improvement compared to our previous reports for PTE synthesized in a similar fashion and hence validated that the recombinant protein was properly expressed and incubated. ${ }^{33,56}$

The PtNP-IML-PGE was biofunctionalized with PTE enzymes by covalent cross-linking with glutaraldehyde and albumin. Glutaraldehyde cross-linking offers a straightforward and inexpensive approach to immobilizing enzymes onto electrode surfaces and in particular has shown to enhance the biosensor thermostability, reusability, and shelf-life when used to covalently link enzymes to graphene/graphene oxide electrodes. ${ }^{57-59}$ Distinct concentrations of glutaraldehyde $(0.125,0.175,0.25,0.325$, and $0.5 \%)$ within a BSA/PTE mixture were tested to determine which improved the biosensor sensitivity the most (Supporting Information Figure S8). Increasing the concentration of glutaraldehyde from 0.125 to $0.25 \%$ significantly improved the biosensor sensitivity to paraoxon (most likely through increased loading of active enzyme on the electrode surface). However, the sensitivity begins to decrease after glutaraldehyde concentrations of $0.25 \%$ due to an increased diffusion barrier which hinders paraoxon from binding to the enzyme and impedes $p$-nitrophenol from reaching the graphene transduction material after catalysis.

3.2. Biosensor Performance Characterization. 3.2.1. Initial Calibration. The PTE-biofunctionalized PtNP-IML-PGE was first calibrated in buffer solution via amperometry at an applied $+0.95 \mathrm{~V}$ versus $\mathrm{Ag} / \mathrm{AgCl}$ (Figure 6a). The biosensor was capable of rapidly monitoring (response time $<10 \mathrm{~s}$ ) successive paraoxon concentration increases with distinct amperometric response signals for consecutive $0.1 \mu \mathrm{M}$ paraoxon additions (blue arrows) and $1 \mu \mathrm{M}$ concentration additions (red arrows). The biosensor displayed a semilinear characteristic calibration plot that can be fitted with a secondorder polynomial $\left(i_{\mathrm{pa}}=-0.011[\text { paraoxon }]^{2}+0.350\right.$ [paraoxon], where $i_{\mathrm{pa}}$ is the peak anodic current response with a coefficient of determination $\left(R^{2}\right)$ of 0.995 . However, a linear fit of this calibration plot $\left(i_{\mathrm{pa}}=0.263[\right.$ paraoxon] $)$ yielded a lower $R^{2}$ value (0.978). This deviation from linearity is most likely due to the increased diffusion layer caused by the glutaraldehyde crosslinking that limits the diffusion of paraoxon to the enzyme as well as the product ( $p$-nitrophenol) to the electrode surface. Note that both the PtNP-IML-PGE and IML-PGE were biofunctionalized and linearly calibrated (Figure 6b); PtNPIML-PGE displayed a higher sensitivity $(370 \mathrm{nA} / \mu \mathrm{M})$ and lower detection limit $(3 \mathrm{nM}, \mathrm{S} / \mathrm{N}=3)$ than the PTEbiofunctionalized IML-PGE (270 nA/ $\mu \mathrm{M}$ and $12 \mathrm{nM})$.

These biosensor results compare quite favorably with other paraoxon electrochemical biosensors. For example, the PtNPIML-PGE biosensor displayed the highest sensitivity and lowest detection limit of any reported electrochemical biosensor that 

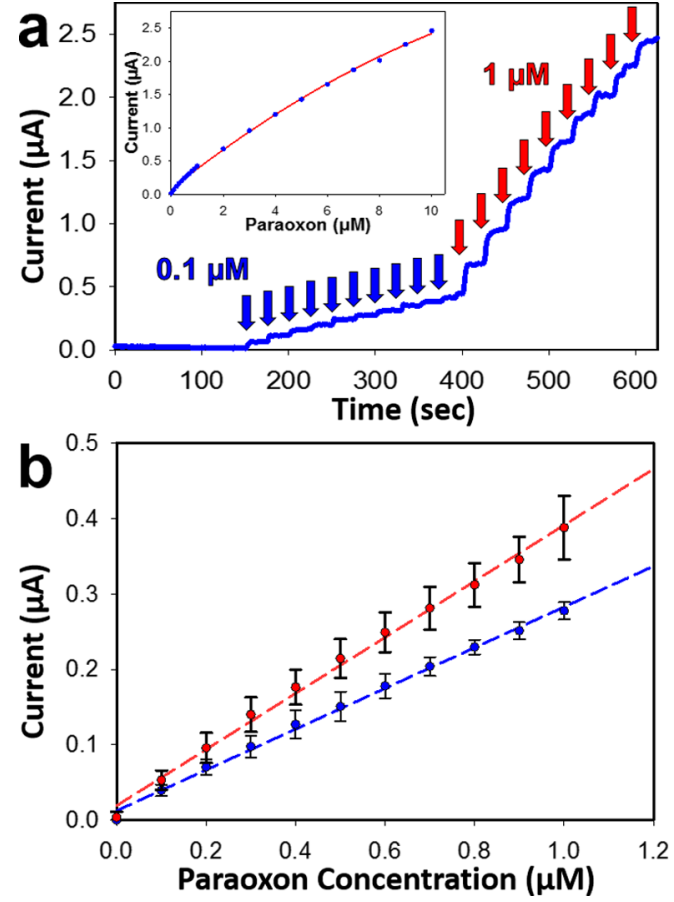

Figure 6. Biosensor calibration plots. (a) Amperometric response of paraoxon additions: $0.1 \mu \mathrm{M}$ additions (blue arrows) and $1 \mu \mathrm{M}$ additions (red arrows) for the PTE functionalized PtNP-IML-PGE. Inset: corresponding concentration vs current graph (second-order polynomial fit). (b) Paraoxon concentration vs amperometric current response for the IML-PGE (blue) and the PtNP-IML-PGE (red) (linear fit). Error bars are standard deviation of three runs $(n=3)$.

utilizes the PTE enzyme to detect paraoxon (Table 1). Note that the PtNP-IML-PGE biosensor paraoxon sensitivity, detection limit, and linear range reported in Table 1 were all calculated using the linear fit to the calibration plot to be congruent with standard reporting practices (Figure 6b). The developed biosensor could also be implemented into high- volume manufacturing protocols (e.g., roll-to-roll polymer printing and graphene coating) as there is no need for photolithography steps, and electrode patterning can be conducted on flexible, disposable substrates. Additionally, the biosensor design eliminated the need for multiple processing and sensing steps (e.g., electrode polishing, multiple electrodeposition steps, a Faraday cage, flow injection, or ion exchange membranes) that have been reported with previous paraoxon biosensors (Table 1).

3.2.2. Stability and Reusability. The PTE-biofunctionalized PtNP-IML-PGE also demonstrated a high degree of stability, reusability, and selectivity. For example, the biosensor retains a steady (90\%) anodic current over $1000 \mathrm{~s}$ after $1 \mu \mathrm{M}$ paraoxon concentration additions, demonstrating little surface polymerization and good operational stability (Figure 7a). Such resistance to surface fouling may be due to the hydrophobic nature of the laser-annealed IML-PGE, as previously mentioned. Long-term biosensor stability was evaluated by testing the biosensors each week for 8 weeks (note that the biosensors were stored at $4{ }^{\circ} \mathrm{C}$ when testing was not occurring.). The biosensor retained nearly 70 and $50 \%$ of initial sensitivity to paraoxon for PtNP-IML-PGE and IMLPGE, respectively (Figure $7 \mathrm{~b}$ ). This retainment in enzyme activity could be attributed to the biocompatibility of the graphene as well as the strong cross-linking of glutaraldehyde, all of which may prevent enzyme denaturation. The biosensor also demonstrated a strong degree of reusability and retained 95\% sensitivity to paraoxon even after 12 repeated uses (average of $0.3 \%$ decrease per time sensed, Figure $7 \mathrm{c}$ ). Hence, the original amperometric current response was nearly retained after each of the 12 sensing experiments.

Next, the selectivity of the designed biosensor was evaluated against potentially interfering nerve agents and within actual soil slurries. It should be noted here that OP sensors that rely on PTE are selective as the enzyme specifically targets triple Olinked phosphonate centers such as found in paraoxon, parathion, chlorpyrifos, and chemical warfare agents such as Sarin and Soman. The selectivity of the biosensor was analyzed
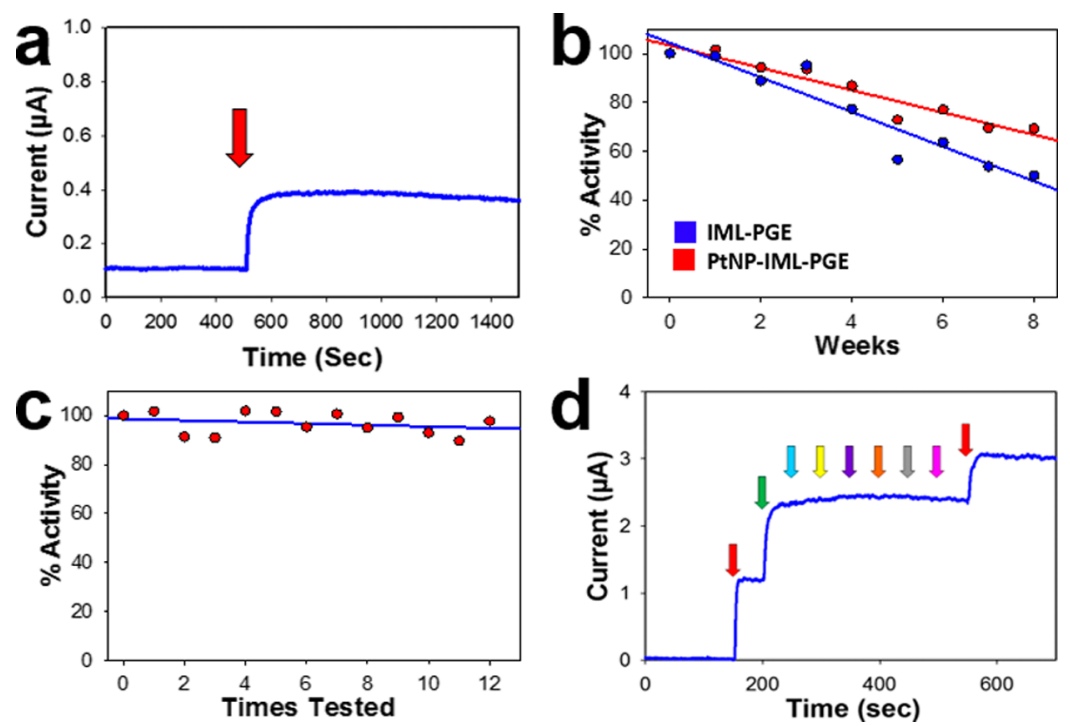

Figure 7. PtNP-IML-PGE biosensor characterization. (a) Stability test: steady oxidation current of a $1 \mu \mathrm{M}$ paraoxon addition over $1000 \mathrm{~s}$. (b) Longevity test: sensitivity of biosensors tested over 1 week intervals. (c) Reusability test: sensitivity of a single biosensor with repeated test runs. (d) Selectivity test: $5 \mu \mathrm{M}$ spikes of paraoxon (red), p-nitrophenol (green), chlorpyrifos methyl (blue), parathion (yellow), dichlofenthion (purple), fenitrothion (orange), phoxim (gray), and dimethoate (pink). 
during amperometry by adding OP concentrations ( $5 \mu \mathrm{M}$ additions) into buffer solution along with various pesticides. The biosensor exhibited a large current increase for paraoxon and $p$-nitrophenol, but a negligible response for methyl parathion and chlorpyrifos (Figure $7 \mathrm{~d}$ ). The biosensors inability to detect these ubiquitous phosphates is consistent with the reported class of PTE that catalyzes these pesticides at a much slower rate. ${ }^{51,54,62}$ Additional pesticides that do not contain phenolic-leaving groups or are not catalyzed by PTE (dichlofenthion, fenitrothion, phoxim, and dimethoate) were also tested and do not show any substantial increase in oxidation current. Paraoxon was then added again to the solution, and a similar step height was observed demonstrating that the immobilized PTE was still active. The biosensor was next tested in a variety of biological solutions (tap water, river water, and a soil slurry) to evaluate its selectivity within actual biological matrices. All solutions were filtered with a $0.45 \mu \mathrm{m}$ syringe filter, $\mathrm{pH}$ adjusted to 8.0 with $\mathrm{NaOH}$, and ionic strength increased to $0.01 \mathrm{M}$ PBS. The biosensor was able to detect low levels $(5 \mu \mathrm{M})$ of paraoxon in a variety of real-world solution media (Table 2). All biosensor test results were within

Table 2. Performance of the Designed Biosensor in a Variety of Media

\begin{tabular}{lccc}
\multicolumn{1}{c}{ solution } & $\begin{array}{c}\text { addition spiked } \\
(\mu \mathrm{M})\end{array}$ & $\begin{array}{c}\text { concentration detected } \\
(\mu \mathrm{M})\end{array}$ & $\begin{array}{c}\text { accuracy } \\
(\%)\end{array}$ \\
tap water & 5 & 5.35 & 107 \\
river water & 5 & 5.10 & 102 \\
soil slurry & 5 & 4.75 & 95 \\
\hline
\end{tabular}

$10 \%$ of pure buffer solutions (based on second-order polynomial calibration plot, Figure 6a), demonstrating that the biosensor is amendable to in-field or point-of-service testing in water and soil samples.

\section{CONCLUSIONS}

In conclusion, an amperometric biosensor for the detection of OPs (paraoxon) has been developed based on a printed graphene electrode (PGE) that has been nano/microstructured with post-print laser processing and electrodeposited platinum nanoparticles (PtNPs) as well as biofunctionalized with the enzyme phosphotriesterase (PTE) via glutaraldehyde crosslinking. The nano/microstructured printed graphene provides an effective transduction material for rapidly monitoring the oxidation of $p$-nitrophenol because of its high electrical conductivity, electroactive nature, and biocompatibility. The graphene transduction layer was further enhanced through laser annealing, which fused individual graphene flakes together, increased the electroactive surface area, and provided stable attachment locations for covalent enzyme functionalization with the increased superficial oxygen groups. The high surface area creates a hydrophobic biosensor that resists surface fouling by repelling nonspecific species from adsorbing on the electrode surface. The PtNPs were utilized to further increase the sensitivity of the biosensor by increasing the electroactive nature of the PGE. The resulting biosensor exhibited the lowest detection limit ( $3 \mathrm{nM})$ and highest sensitivity $(370 \mathrm{nA} / \mu \mathrm{M})$ of any electrochemical PTE biosensor. The designed biosensor displayed a stable response to paraoxon (retained $90 \%$ anodic current over $1000 \mathrm{~s}$ ), long-term stability (70\% over 8 weeks), reusability ( $90 \%$ after 12 repeated scans), and high selectivity to paraoxon. Finally, the biosensors were tested in real samples (tap water, river water, and a soil slurry) to demonstrate its effectiveness during sensing in biological matrices.

IML provides a rapid and low-cost process to manufacture highly defined graphene electrodes for electrochemical sensing. The PtNP-IML-PGEs can also be fabricated with high-volume manufacturing processes (e.g., roll-to-roll processing) as they does not require high-cost photolithography steps and can be patterned on low-cost, disposable substrates. The designed biosensor utilizes PTE that is selective to triple O-linked phosphonate centers; therefore, it is advantageous over cholinesterase biosensors which require additional substrates, incubation periods, and are not selective to only OPs. In-field application of this biosensor could present farmers with a rapid, point-of-application sensor to monitor pesticide levels, which allows for a more accurate application of OPs, decreasing negative environmental impacts. The biosensor could be employed for drinking water testing ${ }^{63,64}$ or defense threat monitoring, ${ }^{20,65}$ via a Boolean enzyme cascade, for example, to provide high fidelity warnings for proactive measures to be taken to protect human life. ${ }^{66}$ Additionally, because the printing, laser annealing, and functionalization protocols can all be performed on thermally and chemically sensitive materials (e.g., polymers and paper), the developed graphenebased OP biosensor could be incorporated into wearable ringbased, glove-based, or textile-based sensor platforms for rapid in-field analysis and defense threat awareness of nerve agents. ${ }^{67}$ Finally, the PtNP-IML-PGE fabrication protocol could be used for the scalable manufacturing of printed graphene-based electrodes for other applications in addition to biosensors including high-performance supercapacitors, ${ }^{68}$ biofuel cells, ${ }^{69}$ as well as dye-sensitized solar cells. ${ }^{70}$

\section{ASSOCIATED CONTENT}

\section{Supporting Information}

The Supporting Information is available free of charge on the ACS Publications website at DOI: 10.1021/acsami.7b19763.

SEM micrographs of PGEs laser-annealed at various carving times; SEM micrographs of PGEs functionalized with PtNPs electrodeposited at distinct deposition cycles; sensitivity and detection limit of the PtNP-IMLPGE biosensor depending on $\mathrm{pH}$ and applied potential; sheet resistance of IML-PGE based on laser carving time; cyclic voltammograms of the SPCE, IML-PGE, and PtNP-IML-PGE with various scan rates in ferro/ ferricyanide; cyclic voltammograms of the SPCE, IMLPGE, and PtNP-IML-PGE in buffer and $1 \mathrm{mM} p$ nitrophenol; and amperometric and sensitivity graphs for the PtNP-IML-PGE functionalized with enzyme crosslinked with various concentrations of glutaraldehyde (PDF)

IML graphene electrode fabrication via the IML technique: Graphene lift-off on a flexible Kemafoil substrate within an acetone bath and subsequent impingement with an acetone wash bottle (AVI)

\section{AUTHOR INFORMATION}

\section{Corresponding Author}

*E-mail: jcclauss@iastate.edu. Phone: 515-294-4690.

ORCID (8)

John A. Hondred: 0000-0001-9913-7223

Scott A. Walper: 0000-0002-9436-3456

Igor L. Medintz: 0000-0002-8902-4687 
Jonathan C. Claussen: 0000-0001-7065-1077

Notes

The authors declare no competing financial interest.

\section{ACKNOWLEDGMENTS}

J.C.C. gratefully acknowledges funding support for this work by the National Institute of Food and Agriculture, U.S. Department of Agriculture, under award number 2016-67021-25038 and project accession number 11901762, the National Science Foundation under award number CBET-1706994, as well as by the Iowa State University College of Engineering and Department of Mechanical Engineering.

\section{REFERENCES}

(1) Enserink, M.; Hines, P. J.; Vignieri, S. N.; Wigginton, N. S.; Yeston, J. S. The Pesticide Paradox. Science 2013, 341, 730-731.

(2) Fenner, K.; Canonica, S.; Wackett, L. P.; Elsner, M. Evaluating pesticide degradation in the environment: blind spots and emerging opportunities. Science 2013, 341, 752-758.

(3) Brown, M. A.; Brix, K. A. Review of health consequences from high-, intermediate-and low-level exposure to organophosphorus nerve agents. J. Appl. Toxicol. 1998, 18, 393-408.

(4) Munro, N. B.; Talmage, S. S.; Griffin, G. D.; Waters, L. C.; Watson, A. P.; King, J. F.; Hauschild, V. The sources, fate, and toxicity of chemical warfare agent degradation products. Environ. Health Perspect. 1999, 107, 933.

(5) Kim, K.; Tsay, O. G.; Atwood, D. A.; Churchill, D. G. Destruction and detection of chemical warfare agents. Chem. Rev. 2011, 111, 5345-5403.

(6) Yanagisawa, N.; Morita, H.; Nakajima, T.; Okudera, H.; Shimizu, M.; Hirabayashi, H.; Nohara, M.; Midorikawa, Y.; Mimura, S. Sarin poisoning in Matsumoto, Japan. Lancet 1995, 346, 290-293.

(7) Okumura, T.; Takasu, N.; Ishimatsu, S.; Miyanoki, S.; Mitsuhashi, A.; Kumada, K.; Tanaka, K.; Hinohara, S. Report on 640 victims of the Tokyo subway sarin attack. Ann. Emerg. Med. 1996, 28, 129-135.

(8) Muñoz-Quezada, M. T.; Lucero, B. A.; Iglesias, V. P.; Muñoz, M. P.; Cornejo, C. A.; Achu, E.; Baumert, B.; Hanchey, A.; Concha, C.; Brito, A. M. Chronic exposure to organophosphate (OP) pesticides and neuropsychological functioning in farm workers: a review. Int. J. Occup. Environ. Health 2016, 22, 68-79.

(9) Rothlein, J.; Rohlman, D.; Lasarev, M.; Phillips, J.; Muniz, J.; McCauley, L. Organophosphate pesticide exposure and neurobehavioral performance in agricultural and nonagricultural Hispanic workers. Environ. Health Perspect. 2006, 114, 691.

(10) Zhang, X.; Wu, M.; Yao, H.; Yang, Y.; Cui, M.; Tu, Z.; Stallones, L.; Xiang, H. Pesticide poisoning and neurobehavioral function among farm workers in Jiangsu, People's Republic of China. Cortex 2016, 74, 396-404.

(11) Raanan, R.; Balmes, J. R.; Harley, K. G.; Gunier, R. B.; Magzamen, S.; Bradman, A.; Eskenazi, B. Decreased lung function in 7-year-old children with early-life organophosphate exposure. Thorax 2016, 71, 148-153.

(12) Jaipieam, S.; Visuthismajarn, P.; Sutheravut, P.; Siriwong, W.; Thoumsang, S.; Borjan, M.; Robson, M. Organophosphate pesticide residues in drinking water from artesian wells and health risk assessment of agricultural communities, Thailand. Hum. Ecol. Risk Assess. 2009, 15, 1304-1316.

(13) Fries, E.; Püttmann, W. Monitoring of the three organophosphate esters TBP, TCEP and TBEP in river water and ground water (Oder, Germany). J. Environ. Monit. 2003, 5, 346-352.

(14) USDA-PDA. Pesticide Data Program Annual Summary, Calendar Year 2008. Available at: http://www.ams.usda.gov/pdp, 2008.

(15) USDA. USDA: Pesticide Data Program Analytical Methods. Available at: http://www.ams.usda.gov/AMSv1.0/getfile?dDocName= STELPRDC5049940, 2010.
(16) Fenske, R. A.; Black, K. G.; Elkner, K. P.; Lee, C.-L.; Methner, M. M.; Soto, R. Potential exposure and health risks of infants following indoor residential pesticide applications. Am. J. Publ. Health Res. 1990, 80, 689-693.

(17) Mulchandani, A.; Mulchandani, P.; Chen, W.; Wang, J.; Chen, L. Amperometric thick-film strip electrodes for monitoring organophosphate nerve agents based on immobilized organophosphorus hydrolase. Anal. Chem. 1999, 71, 2246-2249.

(18) Vo-Dinh, T.; Cullum, B. Biosensors and biochips: advances in biological and medical diagnostics. Fresenius. J. Anal. Chem. 2000, 366, $540-551$.

(19) Kirsch, J.; Siltanen, C.; Zhou, Q.; Revzin, A.; Simonian, A. Biosensor technology: recent advances in threat agent detection and medicine. Chem. Soc. Rev. 2013, 42, 8733-8768.

(20) Verma, N.; Bhardwaj, A. Biosensor technology for pesticides-a review. Appl. Biochem. Biotechnol. 2015, 175, 3093-3119.

(21) Arduini, F.; Forchielli, M.; Amine, A.; Neagu, D.; Cacciotti, I.; Nanni, F.; Moscone, D.; Palleschi, G. Screen-printed biosensor modified with carbon black nanoparticles for the determination of paraoxon based on the inhibition of butyrylcholinesterase. Microchim. Acta 2015, 182, 643-651.

(22) Kesik, M.; Kanik, F. E.; Turan, J.; Kolb, M.; Timur, S.; Bahadir, M.; Toppare, L. An acetylcholinesterase biosensor based on a conducting polymer using multiwalled carbon nanotubes for amperometric detection of organophosphorous pesticides. Sens. Actuators, B 2014, 205, 39-49.

(23) Guilhermino, L.; Barros, P.; Silva, M. C.; Soares, A. M. V. M. SHORT COMMUNICATION Should the use of inhibition of cholinesterases as a specific biomarker for organophosphate and carbamate pesticides be questioned. Biomarkers 1998, 3, 157-163.

(24) Bigley, A. N.; Raushel, F. M. Catalytic mechanisms for phosphotriesterases. Biochim. Biophys. Acta, Biophys 2013, 1834, $443-453$.

(25) Alizadeh, T.; Ganjali, M. R.; Norouzi, P.; Zare, M.; Zeraatkar, A. A novel high selective and sensitive para-nitrophenol voltammetric sensor, based on a molecularly imprinted polymer-carbon paste electrode. Talanta 2009, 79, 1197-1203.

(26) Hu, Y.-f.; Zhang, Z.-h.; Zhang, H.-b.; Luo, L.-j.; Yao, S.-z. Sensitive and selective imprinted electrochemical sensor for $\mathrm{p}$ nitrophenol based on $\mathrm{ZnO}$ nanoparticles/carbon nanotubes doped chitosan film. Thin Solid Films 2012, 520, 5314-5321.

(27) Arvinte, A.; Mahosenaho, M.; Pinteala, M.; Sesay, A.-M.; Virtanen, V. Electrochemical oxidation of p-nitrophenol using graphene-modified electrodes, and a comparison to the performance of MWNT-based electrodes. Microchim. Acta 2011, 174, 337-343.

(28) Chough, S. H.; Mulchandani, A.; Mulchandani, P.; Chen, W.; Wang, J.; Rogers, K. R. Organophosphorus hydrolase-based amperometric sensor: modulation of sensitivity and substrate selectivity. Electroanalysis 2002, 14, 273.

(29) Li, J.; Kuang, D.; Feng, Y.; Zhang, F.; Xu, Z.; Liu, M. A graphene oxide-based electrochemical sensor for sensitive determination of 4 nitrophenol. J. Hazard. Mater. 2012, 201, 250-259.

(30) Mulchandani, P.; Hangarter, C. M.; Lei, Y.; Chen, W.; Mulchandani, A. Amperometric microbial biosensor for p-nitrophenol using Moraxella sp.-modified carbon paste electrode. Biosens. Bioelectron. 2005, 21, 523-527.

(31) Van Dyk, J. S.; Pletschke, B. Review on the use of enzymes for the detection of organochlorine, organophosphate and carbamate pesticides in the environment. Chemosphere 2011, 82, 291-307.

(32) Hondred, J. A.; Stromberg, L. R.; Mosher, C. L.; Claussen, J. C. High Resolution Graphene Films for Electrochemical Sensing via Inkjet Maskless Lithography. ACS Nano 2017, 11, 9836-9845.

(33) Breger, J. C.; Ancona, M. G.; Walper, S. A.; Oh, E.; Susumu, K.; Stewart, M. H.; Deschamps, J. R.; Medintz, I. L. Understanding how nanoparticle attachment enhances phosphotriesterase kinetic efficiency. ACS Nano 2015, 9, 8491-8503.

(34) Laothanachareon, T.; Champreda, V.; Sritongkham, P.; Somasundrum, M.; Surareungchai, W. Cross-linked enzyme crystals of organophosphate hydrolase for electrochemical detection of 
organophosphorus compounds. World J. Microbiol. Biotechnol. 2008, 24, 3049-3055.

(35) Sahin, A.; Dooley, K.; Cropek, D. M.; West, A. C.; Banta, S. A dual enzyme electrochemical assay for the detection of organophosphorus compounds using organophosphorus hydrolase and horseradish peroxidase. Sens. Actuators, B 2011, 158, 353-360.

(36) Miller, G. C.; Crosby, D. G. Pesticide photoproducts: generation and significance. J. Toxicol., Clin. Toxicol. 1982, 19, 707-735.

(37) Zhang, Y.; Zhang, L.; Zhou, C. Review of chemical vapor deposition of graphene and related applications. Acc. Chem. Res. 2013, 46, 2329-2339.

(38) Claussen, J. C.; Artiles, M. S.; McLamore, E. S.; Mohanty, S.; Shi, J.; Rickus, J. L.; Fisher, T. S.; Porterfield, D. M. Electrochemical glutamate biosensing with nanocube and nanosphere augmented single-walled carbon nanotube networks: a comparative study. J. Mater. Chem. 2011, 21, 11224-11231.

(39) Salinas-Torres, D.; Huerta, F.; Montilla, F.; Morallón, E. Study on electroactive and electrocatalytic surfaces of single walled carbon nanotube-modified electrodes. Electrochim. Acta 2011, 56, 2464-2470.

(40) Das, S. R.; Nian, Q.; Cargill, A. A.; Hondred, J. A.; Ding, S.; Saei, M.; Cheng, G. J.; Claussen, J. C. 3D nanostructured inkjet printed graphene via UV-pulsed laser irradiation enables paper-based electronics and electrochemical devices. Nanoscale 2016, 8, 1587015879 .

(41) Das, S. R.; Srinivasan, S.; Stromberg, L. R.; He, Q.; Garland, N.; Straszheim, W. E.; Ajayan, P. M.; Balasubramanian, G.; Claussen, J. C. Superhydrophobic inkjet printed flexible graphene circuits via directpulsed laser writing. Nanoscale 2017, 9, 19058-19065.

(42) Hondred, J. A.; Stromberg, L. R.; Mosher, C. L.; Claussen, J. C. High Resolution Graphene Films for Electrochemical Sensing via Inkjet Maskless Lithography. ACS Nano 2017, 11, 9836.

(43) Claussen, J. C.; Kumar, A.; Jaroch, D. B.; Khawaja, M. H.; Hibbard, A. B.; Porterfield, D. M.; Fisher, T. S. Nanostructuring platinum nanoparticles on multilayered graphene petal nanosheets for electrochemical biosensing. Adv. Funct. Mater. 2012, 22, 3399-3405.

(44) Dutta, N.; Biswas, S.; Saha, M. K. Biophysical characterization and activity analysis of nano-magnesium supplemented cellulase obtained from a psychrobacterium following graphene oxide immobilization. Chem. Rev. 2016, 95, 248-258.

(45) Takmakov, P.; Zachek, M. K.; Keithley, R. B.; Walsh, P. L.; Donley, C.; McCarty, G. S.; Wightman, R. M. Carbon microelectrodes with a renewable surface. Anal. Chem. 2010, 82, 2020-2028.

(46) Chandra, S.; Miller, A. D.; Bendavid, A.; Martin, P. J.; Wong, D. K. Y. Minimizing fouling at hydrogenated conical-tip carbon electrodes during dopamine detection in vivo. Anal. Chem. 2014, 86, 2443-2450.

(47) Pérez-López, B.; Sola, J.; Alegret, S.; Merkoçi, A. A carbon nanotube PVC based matrix modified with glutaraldehyde suitable for biosensor applications. Electroanalysis 2008, 20, 603-610.

(48) Zhang, H.; Lamb, R.; Lewis, J. Engineering nanoscale roughness on hydrophobic surface-preliminary assessment of fouling behaviour. Sci. Technol. Adv. Mater. 2005, 6, 236-239.

(49) Claussen, J. C.; Kim, S. S.; Haque, A.; Artiles, M. S.; Porterfield, D. M.; Fisher, T. S. Electrochemical glucose biosensor of platinum nanospheres connected by carbon nanotubes. J. Diabetes Sci. Technol. 2010, 4, 312-319.

(50) Pedrosa, V. A.; Paliwal, S.; Balasubramanian, S.; Nepal, D.; Davis, V.; Wild, J.; Ramanculov, E.; Simonian, A. Enhanced stability of enzyme organophosphate hydrolase interfaced on the carbon nanotubes. Colloids Surf., B 2010, 77, 69-74.

(51) Deo, R. P.; Wang, J.; Block, I.; Mulchandani, A.; Joshi, K. A.; Trojanowicz, M.; Scholz, F.; Chen, W.; Lin, Y. Determination of organophosphate pesticides at a carbon nanotube/organophosphorus hydrolase electrochemical biosensor. Anal. Chim. Acta 2005, 530, $185-189$.

(52) Tang, X.; Zhang, T.; Liang, B.; Han, D.; Zeng, L.; Zheng, C.; Li, T.; Wei, M.; Liu, A. Sensitive electrochemical microbial biosensor for p-nitrophenylorganophosphates based on electrode modified with cell surface-displayed organophosphorus hydrolase and ordered mesopore carbons. Biosens. Bioelectron. 2014, 60, 137-142.
(53) Chen, Z.; Wang, J.; Chao, D.; Baikie, T.; Bai, L.; Chen, S.; Zhao, Y.; Sum, T. C.; Lin, J.; Shen, Z. Hierarchical porous LiNil/3Col/ $3 \mathrm{Mn} 1 / 3 \mathrm{O} 2$ nano-/micro spherical cathode material: minimized cation mixing and improved Li+ mobility for enhanced electrochemical performance. Sci. Rep. 2016, 6, 25771.

(54) Zhang, X.; Wu, R.; Song, L.; Lin, Y.; Lin, M.; Cao, Z.; Wu, W.; Mo, Y. Molecular dynamics simulations of the detoxification of paraoxon catalyzed by phosphotriesterase. J. Comput. Chem. 2009, 30, 2388-2401.

(55) Hondred, J. A.; Breger, J. C.; Garland, N. T.; Oh, E.; Susumu, K.; Walper, S. A.; Medintz, I. L.; Claussen, J. C. Enhanced enzymatic activity from phosphotriesterase trimer gold nanoparticle bioconjugates for pesticide detection. Analyst 2017, 142, 3261-3271.

(56) Breger, J. C.; Buckhout-White, S.; Walper, S. A.; Oh, E.; Susumu, K.; Ancona, M. G.; Medintz, I. L. Assembling high activity phosphotriesterase composites using hybrid nanoparticle peptideDNA scaffolded architectures. Nano Futures 2017, 1, 011002.

(57) Su, R.; Shi, P.; Zhu, M.; Hong, F.; Li, D. Studies on the properties of graphene oxide-alkaline protease bio-composites. Bioresour. Technol. 2012, 115, 136-140.

(58) Pavlidis, I. V.; Vorhaben, T.; Tsoufis, T.; Rudolf, P.; Bornscheuer, U. T.; Gournis, D.; Stamatis, H. Development of effective nanobiocatalytic systems through the immobilization of hydrolases on functionalized carbon-based nanomaterials. Bioresour. Technol. 2012, 115, 164-171.

(59) Kishore, D.; Talat, M.; Srivastava, O. N.; Kayastha, A. M. Immobilization of $\beta$-galactosidase onto functionalized graphene nanosheets using response surface methodology and its analytical applications. PLoS One 2012, 7, No. e40708.

(60) Wang, J.; Krause, R.; Block, K.; Musameh, M.; Mulchandani, A.; Schöning, M. J. Flow injection amperometric detection of OP nerve agents based on an organophosphorus-hydrolase biosensor detector. Biosens. Bioelectron. 2003, 18, 255-260.

(61) Kirsch, J.; Davis, V. A.; Simonian, A. L. Direct and Discriminative Detection of Organophosphate Neurotoxins for Food and Agriculture Products; IEEE, 2012; pp 1-4.

(62) Wang, J.; Chen, L.; Mulchandani, A.; Mulchandani, P.; Chen, W. Remote biosensor for in-situ monitoring of organophosphate nerve agents. Electroanalysis 1999, 11, 866-869.

(63) Istamboulie, G.; Fournier, D.; Marty, J.-L.; Noguer, T. Phosphotriesterase: a complementary tool for the selective detection of two organophosphate insecticides: chlorpyrifos and chlorfenvinfos. Talanta 2009, 77, 1627-1631.

(64) Karpuzcu, M. E.; Sedlak, D. L.; Stringfellow, W. T. Biotransformation of chlorpyrifos in riparian wetlands in agricultural watersheds: Implications for wetland management. J. Hazard. Mater. 2013, 244, 111-120.

(65) Mulchandani, A.; Chen, W.; Mulchandani, P.; Wang, J.; Rogers, K. R. Biosensors for direct determination of organophosphate pesticides. Biosens. Bioelectron. 2001, 16, 225-230.

(66) Chuang, M.-C.; Windmiller, J. R.; Santhosh, P.; Ramírez, G. V.; Katz, E.; Wang, J. High-fidelity determination of security threats via a Boolean biocatalytic cascade. Chem. Commun. 2011, 47, 3087-3089.

(67) Mishra, R. K.; Hubble, L. J.; Martín, A.; Kumar, R.; Barfidokht, A.; Kim, J.; Musameh, M. M.; Kyratzis, I. L.; Wang, J. Wearable flexible and stretchable glove biosensor for on-site detection of organophosphorus chemical threats. ACS Sens. 2017, 2, 553-561.

(68) Kang, S.; Lim, K.; Park, H.; Park, J. B.; Park, S. C.; Cho, S.-P.; Kang, K.; Hong, B. H. Roll-to-roll laser-printed graphene-graphitic carbon electrodes for high-performance supercapacitors. ACS Appl. Mater. Interfaces 2017, 10, 1033.

(69) Mano, N.; de Poulpiquet, A. O2 Reduction in Enzymatic Biofuel Cells. Chem. Rev. 2018, 118, 2392-2468.

(70) Liu, H.-W.; Liang, S.-p.; Wu, T.-J.; Chang, H.; Kao, P.-K.; Hsu, C.-C.; Chen, J.-Z.; Chou, P.-T.; Cheng, I.-C. Rapid atmospheric pressure plasma jet processed reduced graphene oxide counter electrodes for dye-sensitized solar cells. ACS Appl. Mater. Interfaces 2014, 6, 15105-15112. 